\title{
Benthic meiofauna as indicator of ecological changes in estuarine ecosystems: The use of nematodes in ecological quality assessment
}

\author{
A.S. Alves ${ }^{\mathrm{a}, \mathrm{d}, *}, \mathrm{H}$. Adão ${ }^{\mathrm{b}, \mathrm{d}}$, T.J. Ferrero ${ }^{\mathrm{c}}$, J.C. Marques ${ }^{\mathrm{a}}$, M.J. Costa ${ }^{\mathrm{d}}$, J. Patrício ${ }^{\mathrm{a}}$ \\ a IMAR - Institute of Marine Research, c/o Department of Life Sciences, Faculty of Sciences and Technology, University of Coimbra, 3004-517 Coimbra, Portugal \\ ${ }^{\mathrm{b}}$ University of Évora, Biology Department, Apartado 94, 7002-554 Évora, Portugal \\ c The Natural History Museum, Department of Zoology, Cromwell Road, London SW7 5BD, UK \\ ${ }^{\mathrm{d}}$ Centre of Oceanography, Faculty of Sciences, University of Lisbon, Campo Grande, 1749-016 Lisbon, Portugal
}

\section{A R T I C L E I N F O}

\section{Article history:}

Received 25 April 2012

Received in revised form 12 July 2012

Accepted 21 July 2012

\section{Keywords:}

Meiobenthos

Free-living nematodes

Indicators

Biodiversity

Estuaries

\begin{abstract}
A B S T R A C T
Estuarine meiofauna communities have been only recently considered to be good indicators of ecological quality, exhibiting several advantages over macrofauna, such as their small size, high abundance, rapid generation times and absence of a planktonic phase. In estuaries we must account not only for a great natural variability along the estuarine gradient (e.g. sediment type and dynamics, oxygen availability, temperature and flow speed) but also for the existence of anthropogenic pressures (e.g. high local population density, presence of harbors and dredging activities).

Spatial and temporal biodiversity patterns of meiofauna and free-living marine nematodes were studied in the Mondego estuary (Portugal). Both taxonomic and functional approaches were applied to nematode communities in order to describe the community structure and to relate it with the environmental parameters along the estuary. At all sampling events, nematode assemblages reflected the estuarine gradient, and salinity and grain size composition were confirmed to be the main abiotic factors controlling the distribution of the assemblages.

Moreover, the low temporal variability may indicate that natural variability is superimposed by the anthropogenic pressures present in some areas of the estuary. The characterization of both meiofauna and nematode assemblages highlighted the usefulness of the integration of both taxonomic and functional attributes, which must be taken into consideration when assessing the ecological status of estuaries.
\end{abstract}

(C) 2012 Elsevier Ltd. All rights reserved.

\section{Introduction}

Meiofauna features are a good indicator of environmental conditions and changes in their density, diversity, structure and functioning may indicate alterations in the system. Although not being included in the biological compartment that needs to be monitored in the scope of the Water Framework Directive (WFD, Directive 2000/60/EC), meiofauna gives valuable information regarding ecosystems health. According to Sheppard (2006), marine scientists need to increase awareness of and emphasize the importance of the many species that have no appeal, which are not attractive and, for the most part, are not seen, like meiofauna.

Despite these difficulties, meiofauna communities are reasonably well characterized around the world, with studies ranging from the deep sea floor to alpine lakes, as well as from tropical

\footnotetext{
* Corresponding author at: IMAR - Institute of Marine Research, c/o Department of Life Sciences, Faculty of Sciences and Technology, University of Coimbra, 3004-517 Coimbra, Portugal.

E-mail address: asalves@uc.pt (A.S. Alves).
}

reefs to polar sea ice (Giere, 2009). In Europe, studies on meiobenthic communities mostly encompass the more northerly estuarine ecosystems (e.g. Warwick and Gee, 1984; Li and Vincx, 1993; Smol et al., 1994; Soetaert et al., 1995; Ferrero et al., 2008). In southern Europe there is a serious gap in knowledge. Particularly in the Iberian Peninsula, there is a lack of information on both spatial and temporal distribution of meiofauna and free living nematodes in estuarine environments, being essential to describe those biodiversity patterns.

Meiobenthic communities provide information of great interest not only due to their important role in marine benthic food chains (Heip et al., 1985; Moens et al., 2005) but also due to their ecological characteristics (small size, high abundance, rapid generation times and absence of a planktonic phase), giving meiofauna several advantages over the commonly used macrofauna communities as monitoring organisms (Kennedy and Jacoby, 1999; Schratzberger et al., 2000; Austen and Widdicombe, 2006). In fact, nematodes have been pointed out as potential indicators of anthropogenic disturbance in aquatic ecosystems (e.g. Coull and Chandler, 1992; Schratzberger et al., 2004; Steyaert et al., 2007; Moreno et al., 2008). The inclusion of information regarding their functional traits 